\section{Information Technology Supports for Student-Centered Language Education}

\author{
Magdolna F. Silye \\ University of Debrecen, Centre for Agricultural Sciences, \\ Faculty of Agricultural Sciences, \\ Centre of Technical Languages Instruction, Debrecen
}

\section{SUMMARY}

With the development of computer-mediated communication, the definition of literacy has gained broader dimensions (Murray, 1991). The ability to use new technologies to access, adapt and make intelligent use of information and knowledge is by now viewed as an additional and essential component of literacy. Today's interpretation of literacy (often referred to as "multiliteracy") must incorporate the communication that takes place through a growing variety of text forms associated with information and multimedia technologies.

Since it is fast becoming a basic instrument for building the literacies required for success in academic and workforce environments, used as a tool, information technology needs to become a critical component of student-centered English language education.

\section{INTRODUCTION}

To be considered literate, students today must acquire a set of skills that will enable them to take advantage of the diverse modes of communication made possible by new technologies and to participate in global learning and working communities (Wiwczaroski, 2002). Although becoming multiliterate is not an easy task for any student, it is especially difficult for EFL (English as a Foreign Language) and ESL (English as a Second Language) students. These students must acquire linguistic competence in a new language and at the same time develop the cognitive and sociocultural/intercultural skills necessary to gain access into the social, academic, and workforce environments of the $21^{\text {st }}$ century. They must become functionally literate, able to speak, understand, read, and write English, as well as use English to acquire, articulate and expand their knowledge. They must also become academically literate, able to read and understand interdisciplinary texts, analyze and respond to those texts through various modes of written and oral discourse, and expand their knowledge. Moreover, they must become critically literate, i.e. must be able to evaluate the validity and reliability of informational sources so that they may draw appropriate conclusions from their findings. Finally, in our digital age of information, students must become electronically literate, able "to select and use electronic tools for communication, construction, research, and autonomous learning” (Shetzer, 1998).

Information technology is becoming a basic and crucial tool for building these skills and literacies required for success in academic and workforce environments. The worldwide communication of information, at the same time, calls for the need of a "lingua franca", a language common to all those using the arsenal of information technology. According to demographic projections, the relative number of English native speakers will decrease compared to the population of the world, while the number of speakers of English as an additional "communicational" language will rapidly increase. The spread of the Internet will allow a growing number of people to read, write, speak and listen to English. It is important to note in this context that the increased global contact brought about in the new network society places the priority on the ability to communicate in a lingua franca, rather than on achieving native-like perfection in the language use. In other words, the emphasis is put on the communicative approach, which posits that the goals of foreign language learning and teaching are 1.) to communicate appropriately with native speakers of the language, 2.) to get to understand others and 3.) to get oneself understood in the process (Kramsch, 1993).

The acquisition of a wide range of competences in English thus privileges certain groups of people, especially those who possess a combination of language mastery and information-based knowledge, and may harm others who have less opportunity to acquire them. All in all, English languge competence, especially when paired with competence in technology, can be viewed as a carrier of inequality between people, which, in turn, must urge educators to tailor their pedagogy to fit to help the handicapped.

\section{INFORMATION TECHNOLOGY SUPPORTS FOR LANGUAGE LEARNING}

Technology has the potential to play a major role in foreign language learning and instruction. Since it is fast becoming a basic instrument for building the literacies required for success in academic and workforce environments, used as a tool for literacy, information technology needs to become a critical component of English language courses.

When students are using information technology as a tool or a support for communicating with others in a foreign language, they are in an active role rather than in the passive role of recipient of information transmitted by a teacher or a textbook. The student is actively making choices about how to generate, obtain, manipulate, or display information. Technology use allows many more students to actively think about information, execute skills that are not common in teacher-led lessons. The teacher's role changes as well. The teacher is no longer the 
center of attention as the pool and dispenser of information, but rather plays the role of facilitator, setting project goals and providing guidelines and resources, moving from student to student or group to group, giving suggestions and support for student activity. The majority of classroom time thus may be devoted to independent and collaborative projects.

Technology facilitates a change in the teacher's role also by making it easier for them to act as a diagnostician and coach for the cognitive aspects of the learning process. Technology can help to join teacher and student together in the students' thinking processes, something that does not happen when students simply turn in a completed test sheet for checking and grading. Technology often puts teachers in the role of learner alongside their students. This is a big change from the traditional image of the teacher seen as the one with all the knowledge and right answers. Instead, students are given the chance to see their teachers struggle with the acquisition of a new set of skills. In addition to helping the teacher with technology, students also support the teacher by providing help to their peers.

\section{THE INTERNET AS A TOOL FOR LANGUAGE} TEACHING

Of the variety of electronic tools, the Internet has a specific potential for promoting the acquisition of linguistic skills and the creative construction of knowledge (Warschauer, 1998). The Internet helps to develop reading and writing skills by providing ready access to a wide range of information resources that might otherwise be unavailable to language learners. Because the language of the Internet is English, at the click of a mouse the students have access to a diverse collection of authentic English language texts dealing with a wide selection of interdisciplinary topics. While encountering these resources, the students can familiarise a wide range of texts, formats and conventions, which provides them with raw or sample materials for various modes of written communication.

For students of English, the key instructional benefit results from the hypermedia and interactive format of the Internet. In this way, the Internet becomes an ideal instructional resource for teaching a wide range of language skills and contents in an integrated manner. At the same time it can provide significant support for the development of studentcentered constructivist learning.

The two models to be reviewed below offer suggestions on the exploration of the pedagogical potentials of the World-Wide Web. They both share the common features of being student-centered, taskbased and project-oriented, and that they provide excellent possibilities for the development of functional, academic, and critical competences, not to mention the enhancement of electronic skills involved. They are also common in that they assign the language instructor a role limited to little more than that of a coach or consultant.

\section{The development of academic writing and reading skills}

The model relies on the methods of content-based language instructional pedagogy, which derives from cognitive learning theory. Cognitive learning theory posits that in the process of acquiring literacy skills, students progress through a series of three stages, the cognitive, the associative, and the autonomous (Anderson, 1983). Progression through these stages is facilitated by providing extensive instructional support during the initial stages of learning and gradually removing this support as students become more proficient at the task (Chamot and O'Malley, 1994). In addition to undergoing an intensive and creative phase of language skills development, students in an academic environment can also reap the benefits for improving their specialist content knowledge.

At the initial phase of the instructional process (several weeks, or months at length), students individually or in teams - chose one subject area of their specialist interest to investigate in depth by exploring Internet resources.

As they are progressing with their web-based research, students are required to complete a range of writing assignments growing in complexity, which scaffolds them toward the composition of a project by the end of the instructional period. In their research, students are required to define and solve problems, to examine evidence collected from a variety of sources and make judgements on the reliability of the data. This provides them with a powerful tool for developing their critical literacy skills. While progressing with their research work, students become familiar with the discourse patterns, rhetorical and communicational conventions of writing in academic English, they acquire linguistic and cognitive skills, and enhance the specialist knowledge of their chosen fields of study. At the same time, they learn how to further knowledge by networking with peers and experts in those fields.

When students are using information technology resources, the assessment of their reading skills development deserves special attention. In such research projects, students have direct and prompt access to a far wider variety of texts than they encounter in a conventional library. When compared to traditional print, reading hypertext is not only a more active, but also a much more interactive process. Traditional print texts are static and unchanging, determined by the interests and purposes of the author. In addition, by following new and different links during a series of online accesses, student readers are continually encountering and, also, creating new texts that furnish them with varied perspectives and views on issues studied as well as with a variety of vocabulary and text structures. Hypertext, thus, encourages students to read widely, and creatively. When students continually engage in this type of extensive and extended reading, vocabulary and language structures become increasingly familiar, intertextual and contextual 
associations become clearer, and a broader base of language competence and knowledge is developed.

\section{The development of sociocultural/intercultural competences}

Language teachers will certainly agree that one of the most essential priorities of language teaching is to study the language in a cultural context. Indeed, language and culture are inseparable. Understanding the culture of the target language enhances understanding of the language, and vice verse. In this respect, the Internet is a valuable source of current information from around the world, students can read hot news in the target language from the target country, which gives them to understand how cultural setting affects one's view of the world.

The development of communicative language teaching in the 1990s was characterized by a growing stress on the merging of language and culture learning (Candlin, 1989; Kramsch, 1993). At the same time a close relationship was noted between the use of a task-based approach and the development of functional learning environments, and the potential of electronic learning networks for enhancing intercultural learning was recognized.

From the pedagigical point of view, the degree to which one is able to understand others and get oneself understood, and to learn interculturally, depends on learners' ability to open up to each other on an emotional level, and on the degree to which they are involved in meaningful activities that allow for negotiation of meaning. In the meaningnegotiation process, learners might strive for at least partial understanding of the communication partner, changing their own perspectives in the process to incorporate aspects of the other's point of view, or even changing their own perspective completely (Bredella, 1992). Central to this process, which is obviously dialogic, are tasks that initiate possible negotiations of meaning.

Candlin (1987) affirms that the exchange between self and other can be enhanced by tasks that allow "learners to become more aware of their own personalities and social roles, and those of their fellow learners..." While tasks highlight "how language is used to reflect and reinforce our value and belief system", Candlin also sees the need "for tasks to take a critical stance" since the improvement of relations between learners' worlds inside and outside the classroom depends "upon mutual acceptance and tolerance of their members, and overcoming the barriers raised by ideology and prejudice” (p. 17).

Questions of task structure, setting, classroom management, and teacher and learner roles are central to the understanding of a task-based language learning approach that facilitates intercultural learning.

A specific feature of the Internet, electronic mail (e-mail) offers authentic means of cross-cultural information exchange organized around and based on tasks. When used in the classroom creatively, e-mail can encourage students to use computers in realistic, authentic situations to develop communicative and thinking skills while generating a powerful pool of intercultural competences. In the assessment of the results of her research, Kroonenberg (1995) concludes that writing on e-mail can be used to generate ideas about a topic, improving thereby functional writing skills and peer interaction.

Such international e-mail networks can have a "free-writing" format or can be organised around a selected content area, either ways, the impetus the exercise gives to the students to develop their creative language skills, intercultural communivcative competences and content knowledge is significant: by stimulating communication, the exercises assist students in developing specific communication skills like arguing, persuading or defending a particular point (F. Silye, 2002). It is important to realize, though, that to enhance intercultural learning, close monitoring (coaching) of the process by which such learning is carried out is essential.

\section{CONCLUSION}

Technology has the potential to play a major role in student-centered foreign language education. Since it is fast becoming a basic instrument for building the literacies required for success in academic and workforce environments, used as a tool for building literacy, information technology needs to become a critical component of English language courses. It is successfully used to design content- and task-based, project-oriented instructional models that strengthen the language competences and literacy skills of students of English, while actively involving them in developing a strong interdisciplinary base of content knowledge.

\section{REFERENCES}

Anderson, J. R. (1983): The architecture of cognition. Cambridge, MA: Harvard University Press

Bredella, L. (1992): Towards a pedagogy of intercultural understanding. Amerikastudien [American Studies], 37. 4. 559-594.

Candlin, C. N. (1987): Towards task-based language learning. In C. N. Candlin-D. Murphy, Language learning tasks pp. 5-22. Englewood Cliffs, NJ: Prentice-Hall International
Candlin, C. N. (1989): Language, culture and curriculum. In C. N. Candlin-T. F. McNamara (Eds.), Language, Learning and Community: Festschrift in honour of Terry R. Quinn pp. 1-24. Sydney: Macquarie University, 1-24.

Chamot, A. U.-O’Malley, J. M. (1994): The CALLA handbook: Implementing the cognitive academic language learning approach. Reading, MA: Addison-Wesley

F. Silye, M. (2002): Electronic Tools for English Language Education, Journal of Agricultural Sciences 1. 
Kasper, L. F. (1997): The Impact of content-based instructional programs on the academic progress of ESL students. English for Specific Purposes 16. 4.

Kramsch, C. (1993): Context and culture in language teaching. Oxford, UK: Oxford University Press

Kroonenberg, N. (1995): Developing communicative and thinking skills via electronic mail TESOL Journal, 4. 2. 24-27.

Murray, D. E. (1991): Coversation for action: The computer terminal as a medium of communication. Amsterdam: John Benjamins
Shetzer, H. (1998, March): Electronic literacies: Bridging the gap. Paper presented at the 1998 conference of Teachers of Speakers of Other Languages, Seattle, WA. Retrieved July 21, 1999, from the World Wide Web: http://www.eslplanet.com/tesol198/literacy/electlit.html

Warschauer, M. (1998): New media, new literacies: Challenges for the next century (http://www.techspecialists.com/ltai/ltai.html) Wiwczaroski, T. (2002): Report writing in ESP Classes, Journal of Agricultural Sciences 1. 